\title{
REGIONAL RESPIRATORY TIME CONSTANTS DURING LUNG RECRUITMENT IN HIGH FREQUENCY OSCILLATORY VENTILATED PRETERM INFANTS
}

\author{
M. Miedema ${ }^{1}$, F. de Jongh ${ }^{1}$, I. Frerichs ${ }^{2}$, M. van Veenendaal ${ }^{1}$, A. van Kaam ${ }^{1}$
}

${ }^{I}$ Emma Children's Hospital / Academic Medical Centre, Amsterdam, The Netherlands, ${ }^{2}$ Anesthesiology and Intensive Care Medicine, University Medical Center Schlesweig-Holstein, Campus Kiel, Kiel, Germany

Background and aims: To assess the regional respiratory time constants of lung volume changes during oxygenation-guided lung recruitment before- and after surfactant treatment in high-frequency oscillatory ventilated preterm infants with respiratory distress syndrome.

Methods: Using electrical impedance tomography, changes in lung volume were continuously recorded during a stepwise recruitment procedure before and after surfactant treatment in 22 preterm infants. Time constants were determined for all incremental and decremental pressure steps, using one phase exponential decay curve fitting. Data were analyzed for the whole cross-section of the chest and the ventral and dorsal lung regions separately.

Results: Before surfactant treatment, the time constants of the incremental pressure steps were significantly longer (median $27.3 \mathrm{~s}$ ) compared to the decremental steps (16.1 s). Regional analysis showed only small differences between the ventral and dorsal lung regions. Following surfactant treatment, the time constants during decremental pressure steps almost tripled to $44.3 \mathrm{~s}$. Furthermore, the time constants became significantly longer in the dorsal (61.2 s) than in to the ventral (40.3 s) lung region.

Conclusions: Lung volume stabilization during stepwise oxygenation-guided lung recruitment in highfrequency oscillatory ventilated preterm infants with respiratory distress syndrome is usually completed within 5 minutes and is dependent on the position of ventilation on the pressure volume curve, the surfactant status and the region of interest of the lung 